\title{
Technical aspects of robotic posterior mitral valve leaflet repair
}

\author{
Hoda Javadikasgari, Rakesh M. Suri, Tomislav Mihaljevic, Stephanie Mick, A. Marc Gillinov \\ Department of Thoracic and Cardiovascular Surgery, Heart and Vascular Institute, Cleveland Clinic, Cleveland, OH, USA \\ Correspondence to: A. Marc Gillinov, MD. Department of Thoracic and Cardiovascular Surgery, Cleveland Clinic, 9500 Euclid Avenue/Desk J4-1, \\ Cleveland, OH 44195, USA. Email: gillinom@ccf.org.
}

\begin{abstract}
Posterior mitral valve leaflet repair is safe, effective and durable and can be performed through conventional sternotomy or by using minimally invasive thoracoscopic or robotic-assisted approaches. Triangular resection with ventricularization, quadrangular resection with sliding or folding leaflet reconstruction, neochordae implantation and edge-to-edge leaflet repair are different techniques for eliminating the prolapsing mitral leaflet segment and restoring normal leaflet coaptation. Recent studies have demonstrated that minimally invasive approaches are associated with a reduced risk of postoperative complications, shorter hospital stay and improved cosmetic outcomes when compared to conventional sternotomy. In this review, we sought to describe technical aspects of robotic posterior mitral valve repair.
\end{abstract}

Keywords: Mitral valve prolapse; repair; posterior

Submitted Feb 16, 2016. Accepted for publication Aug 08, 2016.

doi: 10.21037 /acs.2016.11.02

View this article at: http://dx.doi.org/10.21037/acs.2016.11.02

\section{Introduction}

It is well documented that mitral valve repair confers superior survival and clinical outcomes when compared to valve replacement in patients with degenerative mitral valve disease. Posterior leaflet prolapse is the most common finding in patients with degenerative mitral valve disease (1). Dr McGoon introduced a plication technique to manage the flail segment of the posterior mitral valve. This proved effective in eliminating the prolapsing mitral leaflet segment and durable in restoring normal leaflet coaptation (2). This technique was further modified by performing triangular and quadrangular resection of the redundant myxomatous leaflet tissue.

Robotic mitral valve repair for treating myxomatous mitral valve disease seeks to improve technical precision as well as decrease invasiveness while preserving the safety and effectiveness of surgical mitral valve reconstruction. Herein we review the technical aspects of robotic mitral valve repair for posterior leaflet prolapse.

\section{Operative technique}

The standard surgical protocol for robotic mitral valve repair has been described previously $(3,4)$. Intraoperative transesophageal echocardiography is performed after induction of general anesthesia to delineate mitral valve anatomy in detail. Cardiopulmonary bypass is established by cannulating the femoral artery and vein, with optional cannulation of the superior vena cava through the right internal jugular vein. Robotic mitral valve repair is accomplished with the use of robotic surgical instrumentation via a right sided mini-thoracotomy or endoscopic ports. After pericardiotomy, the ascending aorta is occluded with a transthoracic clamp or an endoballoon.

Ideal patients for posterior leaflet repair have prolapsing, redundant and myxomatous tissue (Figure 1). In such patients, mitral valve repair is accomplished using triangular or quadrangular resection of the prolapsed segment, artificial polytetrafluoroethylene chordae in patients with extensive posterior leaflet prolapse or edge-to-edge leaflet repair in patients with prolapse of lateral or medial posterior leaflet scallops.

Posterior leaflet resection has been the standard treatment for mitral regurgitation (MR) secondary to posterior leaflet prolapse. Triangular resection of the posterior leaflet is performed in the following steps. First, the first normal chordae on either side of the prolapsing 


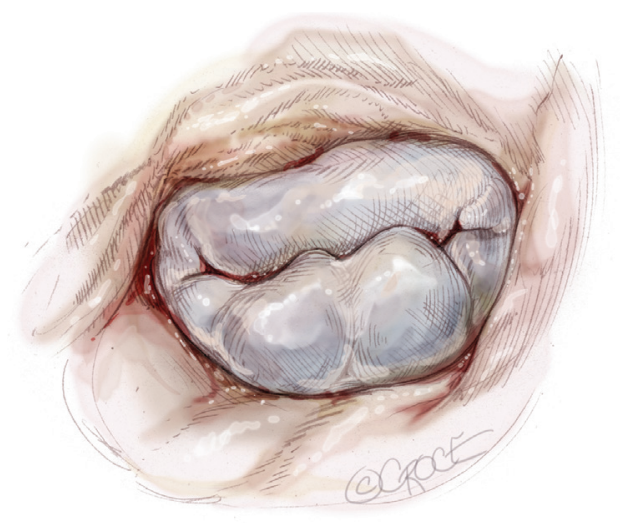

Figure 1 Posterior mitral valve prolapse.

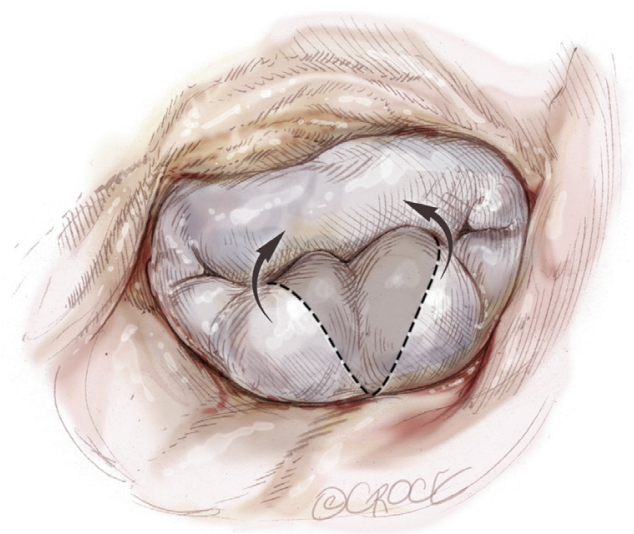

Figure 2 Triangular resection of posterior mitral valve prolapse.

portion need to be identified to determine the extent of required resection. Second, a triangular shaped tissue with its apex at or near the annulus and its base at the free edge of the prolapsing portion is excised (Figure 2). Finally, the defect in the leaflet is closed by either a running 4-0 Prolene suture (Ethicon, Somerville, NJ, USA), or 3-0 Prolene in the case of thick fibrous tissue (Figure 3) (3), or a ventricularization technique (5).

Suture reconstruction using the ventricularization technique is performed to normalize the height of the posterior leaflet and reduce the risk of systolic anterior motion. After triangular resection, each needle of a doublearmed suture is passed through the free edge of one leaflet remnant and then through the mid-portion of that leaflet segment (Figure 4). Tying this suture buries, or 'ventricularize', the free edge thereby reducing the leaflet height (Figure 5). Each needle is then used for a running closure of the posterior leaflet defect and enabling a

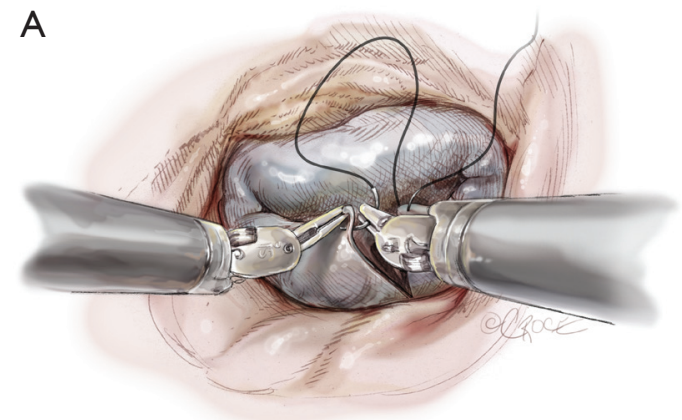

B

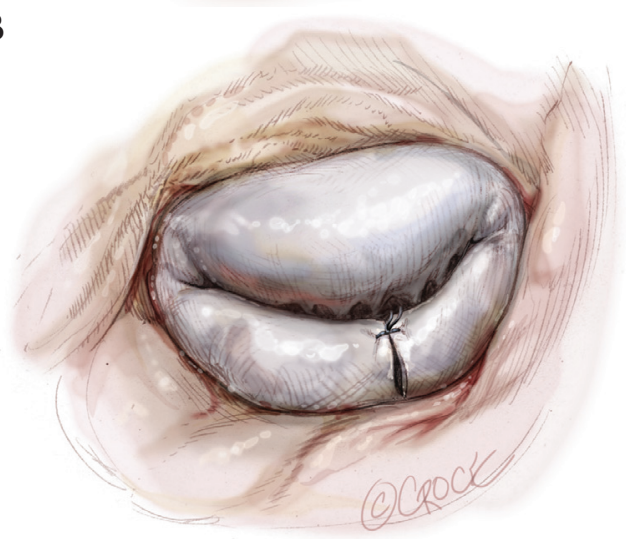

Figure 3 Running suture technique for repair of posterior mitral valve prolapse.

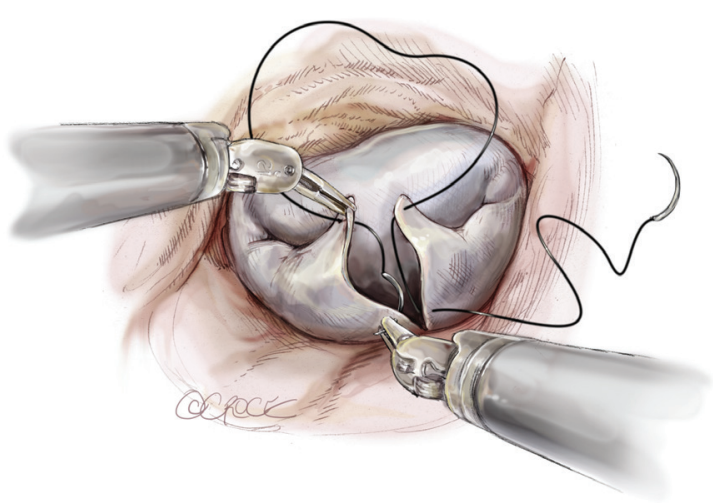

Figure 4 Passing needles of double-armed suture through the free edge of each leaflet and then through the mid-portion of the respective leaflet.

watertight and two-layer suture line (Figure 6). The stitch is tied at the base of the resection, which need not necessarily extend to the mitral annulus (Figure 7).

A larger quadrangular resection with a sliding or folding leaflet reconstruction can be performed when there is an extensive redundant prolapsing segment of the leaflet (Figure 8). 


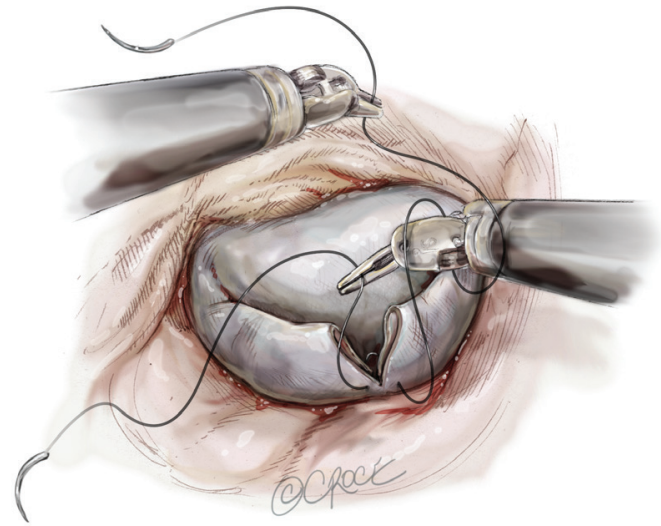

Figure 5 Ventricularization of the remnant leaflets.
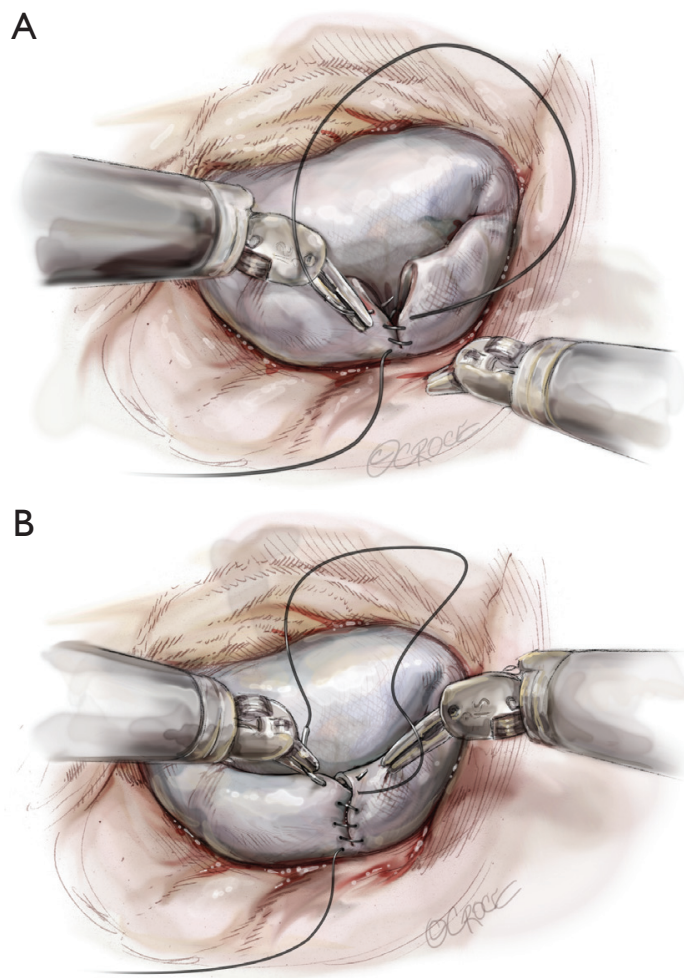

Figure 6 Creating a watertight and double-layer suture line to close posterior leaflet defect.

Neochordae implantation is another option for posterior leaflet repair (Figure 9). The neochordae are created using 5-0 polytetrafluoroethylene monofilament sutures. The anterior leaflet is lifted upward using a dynamic left atrial retractor, which optimizes exposure of the subvalvular apparatus. One arm of the suture is passed twice through the fibrous tip of the papillary muscle, then twice through

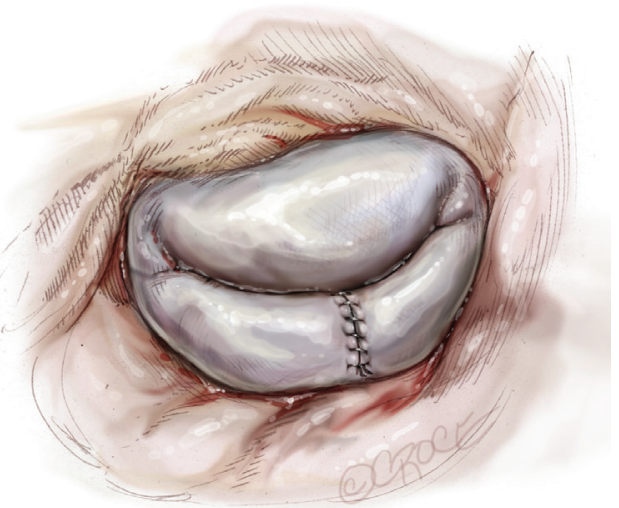

Figure 7 Posterior mitral valve leaflet repair using the ventricularization technique.

the free edge of the corresponding prolapsed segment. The second arm is then passed twice through the free edge of the prolapsing segment. The length of the chordae is adjusted based on the height of the nearest normal segment of the posterior leaflet and the suture is tied on the atrial side of the mitral valve leaflet (6).

Finally, all repairs are completed using a flexible standardlength annuloplasty band. The posterior annuloplasty band is inserted using either running (Figure 10) (7) or interrupted (8) Ethibond sutures from right to left of the fibrous trigone.

All repairs are assessed using a saline infusion to fill and pressurize the left ventricle before closure, de-airing and cross-clamp removal. Integrity of the repair (as defined by mild to absent residual MR) and adequacy of de-airing should be confirmed with the patient off cardiopulmonary bypass before decannulation. All patients should undergo repeated transthoracic echocardiography before discharge from hospital. Lifelong annual echocardiographic surveillance is necessary following mitral valve repair.

\section{Comments}

In 2013, robotic mitral valve repair was performed in 1,132 (12.84\%) of all mitral valve repairs reported to the Society of Thoracic Surgeons' Database. Of these, posterior leaflet repair was the most prevalent procedure. Several recent studies demonstrate that robotic mitral valve repair can be safely and effectively performed for complete correction of all prolapsed categories regardless of complexity of the disease. Although technical complexity of robotic procedures is reflected by longer operative times, reduced invasiveness of this approach is associated with a decreased risk of 

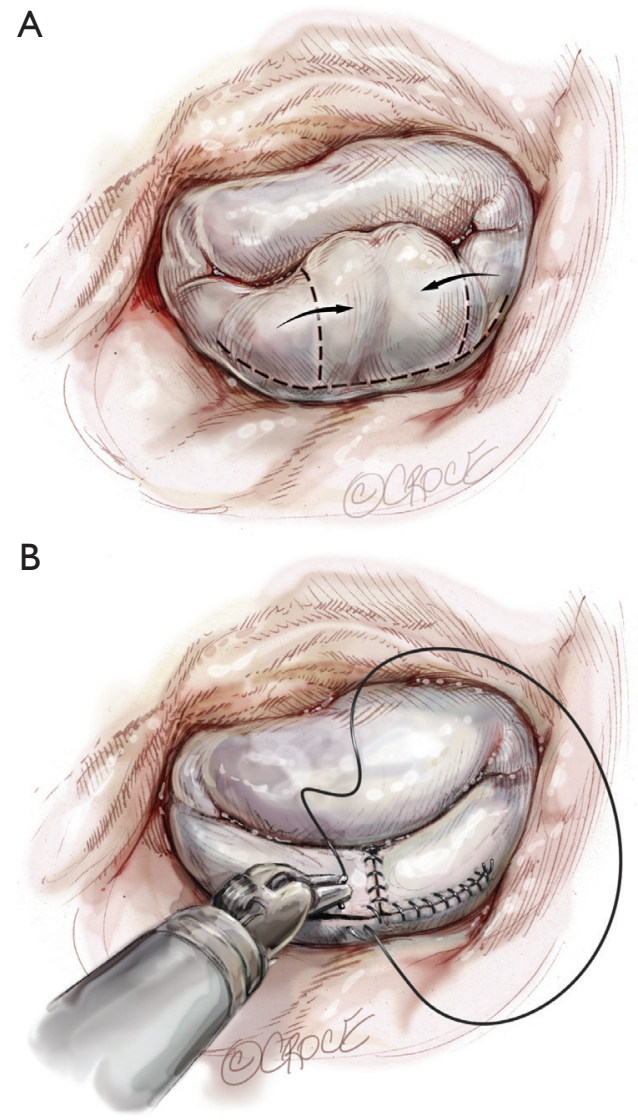

Figure 8 Quadrangular resection for posterior mitral valve repair.

postoperative infection, reduced blood loss and incidence of atrial fibrillation, shorter hospital stay, faster return to normal activity and improved cosmetic results when compared to conventional sternotomy (3,9-12). Furthermore, because of excellent mid-term outcomes, this procedure may be particularly appealing in asymptomatic patients with severe MR and preserved left ventricular function (ACC/AHA class IIa guideline recommendations) (13).

\section{Acknowledgements}

None.

\section{Footnote}

Conflicts of Interest: Dr. Gillinov is a consultant for CryoCath Technologies, Edwards Lifesciences, Medtronic, St. Jude Medical, Abbott Laboratories, and Atricure. The other authors have no conflicts of interest to declare.

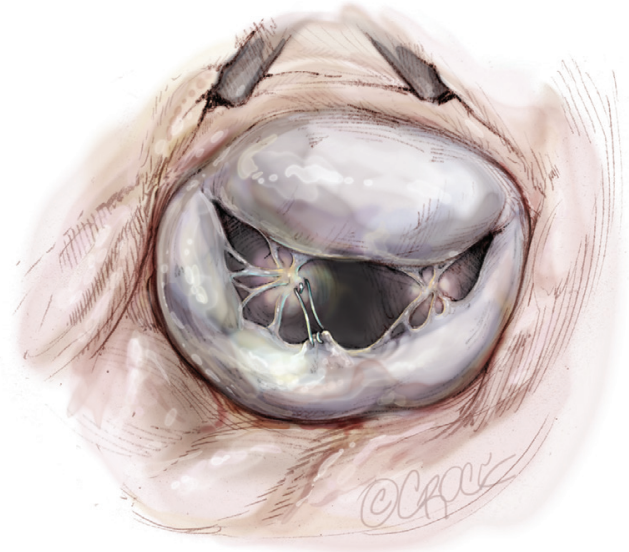

Figure 9 Neochordae implantation for posterior mitral valve repair.

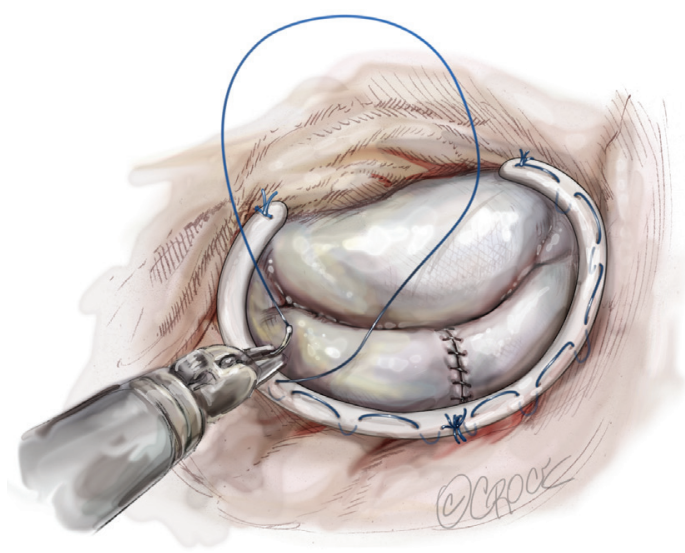

Figure 10 Posterior band annuloplasty using the running suture technique.

\section{References}

1. David TE, Ivanov J, Armstrong S, et al. A comparison of outcomes of mitral valve repair for degenerative disease with posterior, anterior, and bileaflet prolapse. J Thorac Cardiovasc Surg 2005;130:1242-9.

2. McGoon D. Repair of mitral insufficiency due to ruptured chordae tendineae. J Thorac Cardiovasc Surg 1960;39:357-62.

3. Mihaljevic T, Jarrett CM, Gillinov AM, et al. Robotic repair of posterior mitral valve prolapse versus conventional approaches: potential realized. J Thorac Cardiovasc Surg 2011;141:72-80.e1-4.

4. Suri RM, Burkhart HM, Rehfeldt KH, et al. Robotic mitral valve repair for all categories of leaflet prolapse: 
improving patient appeal and advancing standard of care. Mayo Clin Proc 2011;86:838-44.

5. Suri RM, Burkhart HM, Schaff HV. A novel method of leaflet reconstruction after triangular resection for posterior mitral valve prolapse. Ann Thorac Surg 2010;89:e53-6.

6. Mihaljevic T, Pattakos G, Gillinov AM, et al. Robotic posterior mitral leaflet repair: neochordal versus resectional techniques. Ann Thorac Surg 2013;95:787-94.

7. Mihaljevic T, Jarrett CM, Gillinov AM, et al. A novel running annuloplasty suture technique for robotically assisted mitral valve repair. J Thorac Cardiovasc Surg 2010;139:1343-4.

8. Suri RM, Burkhart HM, Daly RC, et al. Robotic mitral valve repair for all prolapse subsets using techniques identical to open valvuloplasty: establishing the benchmark against which percutaneous interventions should be judged. J Thorac Cardiovasc Surg 2011;142:970-9.

9. Suri RM, Taggarse A, Burkhart HM, et al. Robotic Mitral
Valve Repair for Simple and Complex Degenerative Disease: Midterm Clinical and Echocardiographic Quality Outcomes. Circulation 2015;132:1961-8.

10. Murphy DA, Moss E, Binongo J, et al. The Expanding Role of Endoscopic Robotics in Mitral Valve Surgery: 1,257 Consecutive Procedures. Ann Thorac Surg 2015;100:1675-81; discussion 1681-2.

11. Nifong LW, Rodriguez E, Chitwood WR Jr. 540 consecutive robotic mitral valve repairs including concomitant atrial fibrillation cryoablation. Ann Thorac Surg 2012;94:38-42; discussion 43.

12. Ramzy D, Trento A, Cheng W, et al. Three hundred robotic-assisted mitral valve repairs: the Cedars-Sinai experience. J Thorac Cardiovasc Surg 2014;147:228-35.

13. Nishimura RA, Otto CM, Bonow RO, et al. 2014 AHA/ ACC guideline for the management of patients with valvular heart disease: a report of the American College of Cardiology/American Heart Association Task Force on Practice Guidelines. J Am Coll Cardiol 2014;63:e57-185.

Cite this article as: Javadikasgari H, Suri RM, Mihaljevic T, Mick S, Gillinov AM. Technical aspects of robotic posterior mitral valve leaflet repair. Ann Cardiothorac Surg 2016;5(6):577-581. doi: 10.21037/acs.2016.11.02 